\title{
0 fio de Ariadne que nos desvenda o teatro de Alves Redol
}

\section{Maria Helena Serôdio}

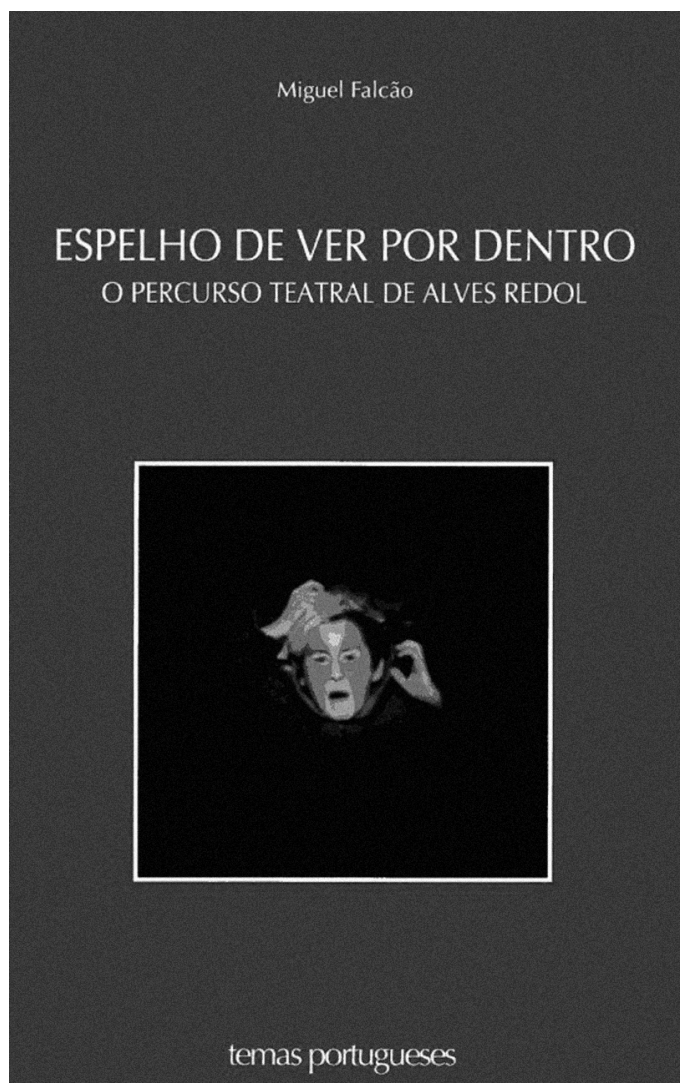

Miguel Falcão, Espelho de ver por dentro: 0 percurso teatral de Alves Redol, Lisboa, Imprensa Nacional - Casa da Moeda, Temas Portugueses, 2009, 717 pp.

1.

Partindo do seu interesse e curiosidade pela personalidade artística e pela obra dramática de Alves Redol, Miguel Falcão iniciou, há alguns anos, uma investigação no âmbito de um Doutoramento em Teatro pela Faculdade de Letras da Universidade de Lisboa.

Trabalhando com um invulgar empenho e rigor, Migue Falcão desenvolveu uma pesquisa aturada em torno do percurso teatral de Alves Redol, o que Ihe permitiu trazer ao conhecimento público uma visão muito completa do envolvimento do escritor com as artes do palco.

A tese, que apresentou em 2006, implicou, de facto, um levantamento e estudo exaustivo da obra - incluindo inúmeros inéditos a que teve acesso através do espólio

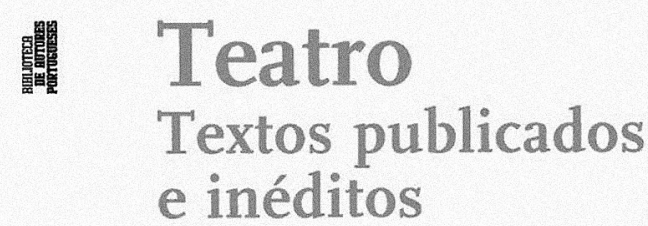

Alves Redol

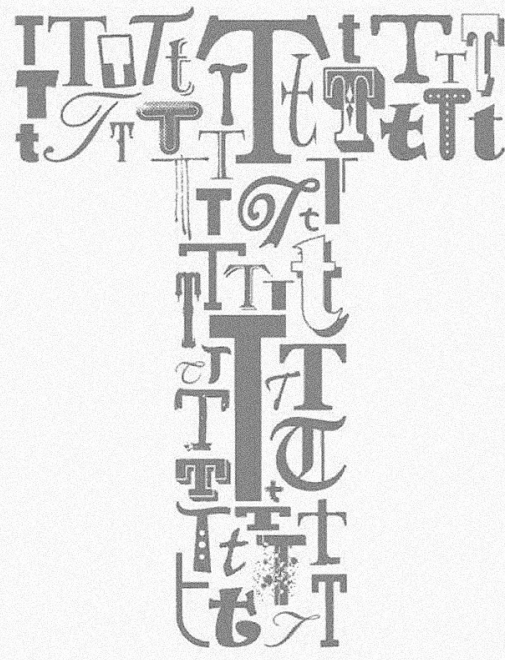

INCH

Alves Redol, Teatro: Textos publicados e inéditos, organização, introdução e notas de Miguel Falcão, Lisboa, Imprensa Nacional - Casa da Moeda, Biblioteca de Autores Portugueses, 2013, 549 pp.

na posse dos herdeiros -, mas incluiu ainda uma vertente de investigação biográfica (sobre as actividades teatrais em que se envolveu o autor), bem como uma informada questionação dos universos conceptuais que no campo do teatro mais terão influenciado a reflexão e a escrita de Redol, tanto na perspectiva da sua dramaturgia, como na animação de projectos de teatro, sobretudo, entre amadores.

Como veio a documentar na sua tese, foi, justamente, no ambiente operário e associativo de Vila Franca de Xira que Alves Redol se iniciou no teatro, participando como actor amador em quatro espectáculos entre 1928 e 1934 e dinamizando iniciativas culturais, que, por vezes, incluiam espectáculos, com actores amadores e profissionais, tanto na sua terra como na Nazaré 

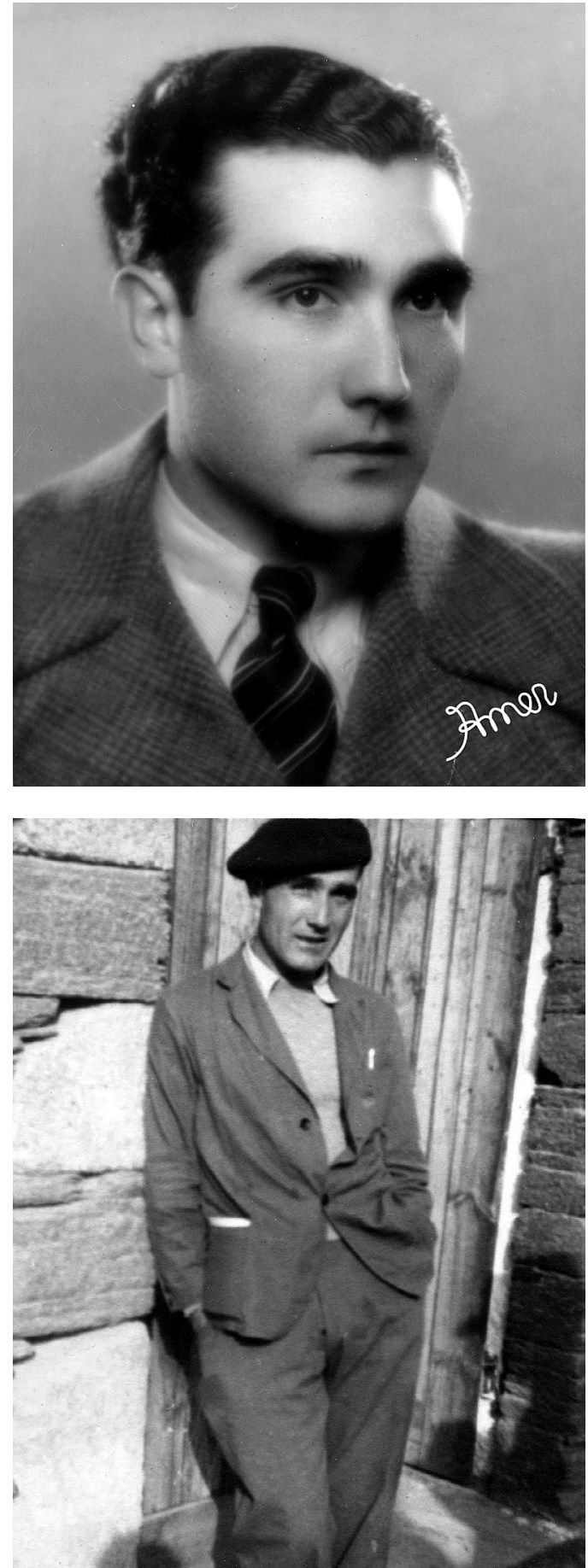

Para melhor enquadrar e perceber o seu trajecto literário e artístico no campo do teatro, Miguel Falcão adoptou uma visão multidisciplinar que integrou a análise dramatúrgica das peças de Alves Redol (incluindo esboços publicados e inéditos), a teorização de teatro - a que teve acesso e o terá influenciado -, a prática cénica e a intervenção cultural - cívica e militante - mais vasta em que decorreram e se articularam todas essas vertentes.

É visivel a seriedade com que foi conduzida a pesquisa em arquivos institucionais - como a Torre do Tombo, o Museu Nacional do Teatro e o Museu do Neo-Realismo -, mas também em espólios particulares - entre cartas e documentação diversa - e, ainda, na leitura de analíticos de periódicos, programas de espectáculos, entre outros materiais que o investigador estudou cuidadosamente. Recolheu ainda testemunhos orais de quem conheceu e acompanhou Alves Redol nas suas actividades culturais de vária índole: os que no teatro o recomendaram para encenação e os que o encenaram e representaram, bem como aqueles que criticamente analisaram o que em cena se fez das suas peças. Nesse sentido, Miguel Falcão não se limitou a trabalhar acervos e espólio, criou ele próprio documentação que pode vir a ser também estudada por outros.

Por todas estas razões, o trabalho de Miguel Falcão veio não apenas revelar obra desconhecida de Alves Redo e analisar o conjunto de uma actuação holística no campo do teatro, mas sobretudo colmatar uma lacuna no que tem sido o estudo da relação entre os autores neo-realistas e a prática teatral.

2.

Foi, por isso, justa e de grande pertinência e valor a opção da Imprensa Nacional - Casa da Moeda em publicar a sua tese Espelho de ver por dentro: O percurso teatral de Alves Redol em 2009.

É, assim, possivel neste livro percebermos que a aproximação ao teatro por parte de Alves Redol se fez também por via ensaistica de cariz etnográfico, tendo publicado, entre outros textos, também em periódicos, uma recolha sobre o tradicional Bicho do Entrudo, em Glória - Uma aldeia do Ribatejo (1938), uma reflexão sobre o teatro levado à cena na França da "Libération", em A França - Da resistência à renascença (1947), e os prefácios às suas peças publicadas na década de 60 , em particular aquele que acompanha 0 destino morreu de repente. É nestes textos, de modo explícito e sistematizado, mas principalmente nas suas peças - nas opções formais que

Alves Redol, 1936 [Espólio do escritor, Arquivo pessoal de António Mota Redol]

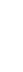


Alves Redol com Manue da Fonseca, anos 40 [Espólio do escritor, Arquivo pessoal de António Mota Redol]. com Jorge Amado e, entre outros, Ferreira de Castro, Alexandre Cabral, Urbano

Tavares Rodrigues Orlando da Costa, anos 60 [Espólio do escritor, Arquivo pessoal de António Mota Redol].

Alves Redol na sua casa do Freixial, anos 50 [Espólio do escritor, Arquivo pessoal d António Mota Redol]
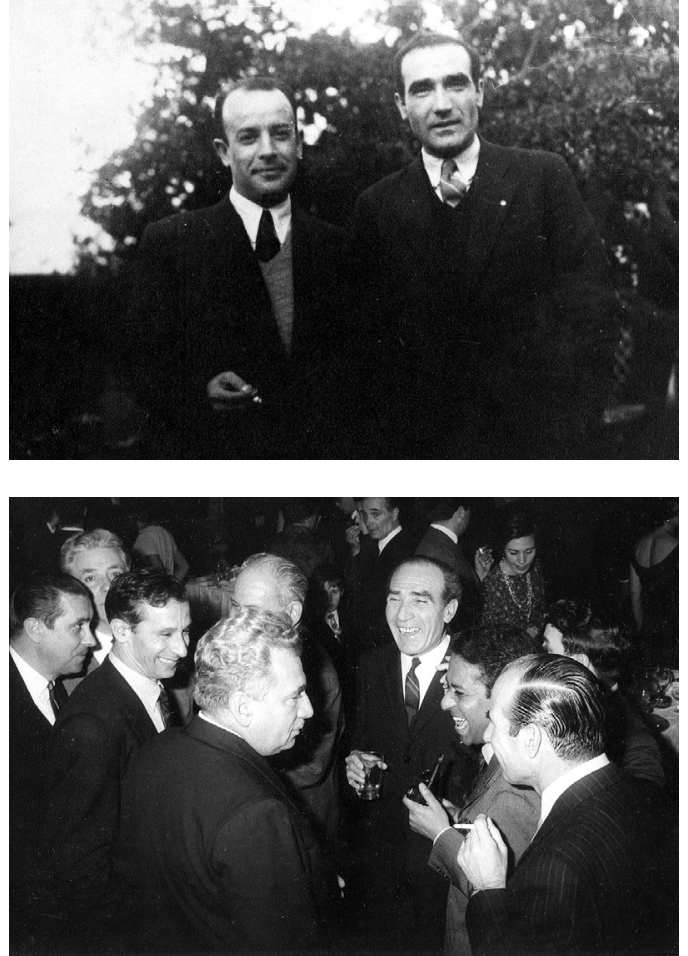

convoca e na dialéctica que nelas estabelece com a interpelação do real - que se revelam as mais importantes referências do seu teatro, que vão da matriz naturalista até ao teatro político de Erwin Piscator e à dramaturgia épica brechtiana, passando pelo teatro popular de Firmin Gémier e Romain Rolland, pelo teatro poético e socialmente comprometido de Federico García Lorca ou pelo drama de alcance social de Henrik Ibsen, George Bernard Shaw e Arthur Miller.

Lemos ainda neste livro de Miguel Falcão que, durante décadas, Alves Redol colaborou no surgimento de vários colectivos teatrais, de entre os quais se destacam, em 1946, o Teatro-Estúdio do Salitre, em Lisboa (com Gino Saviotti, Vasco Mendonça Alves e Luiz Francisco Rebello, entre outros) e, em 1969, o Primeiro Acto (dirigido por Armando Caldas), em Algés.

Assume-se como dramaturgo com Maria Emília, "peça em um acto" que foi publicada na revista Vértice (Maio de 1945) e escolhida, no ano seguinte, para o primeiro espectáculo "essencialista" do Teatro-Estúdio do Salitre, com encenação de António Vitorino. Publicou em livro mais três peças: a tragédia Forja (1948), cuja montagem cénica em Portugal só foi autorizada pela Censura cerca de vinte e um anos mais tarde, no Teatro Laura Alves, com encenação de Jorge Listopad; a "sugestão para um divertimento popular" intitulado 0 destino morreu de repente (1967), parcialmente integrado em 1976 no espectáculo 0 meu caso + 0 destino morreu de repente, do Teatro de Animação de Setúbal, dirigido por Carlos César, e só em 1988 estreado na íntegra pela Comuna Teatro de Pesquisa com encenação de João Mota; o drama Fronteira fechada (publicado postumamente em 1972), levado à cena pela primeira vez na Sociedade Operária de Instrução e Recreio Joaquim António de Aguiar, em Évora, em 1973. A sua obra dramática inclui ainda três peças breves, escritas propositadamente para a cena: Porto de todo o mundo (1943) e De braços abertos para a natureza

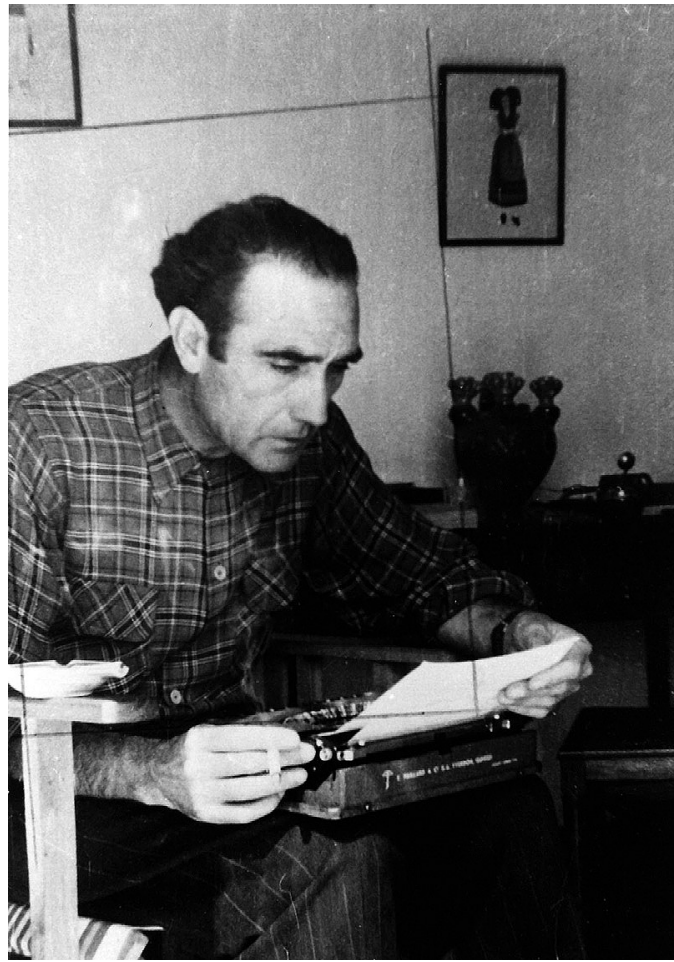

(1950), ambas representadas no âmbito do movimento campista, e 0 menino dos olhos verdes (1950), destinada à estreia de Laura Alves como "actriz dramática".

0 livro integra ainda uma apurada síntese cronológica de Redol, uma minuciosa teatrografia, um bom indice remissivo e, no caso da bibliografia, importantes apontamentos descritivos que em muito ajudam o leitor e investigador.

Destaco não apenas a riqueza de informação que nos chega a propósito da Bibliografia primária (com inestimáveis indicações sobre textos e documentos muito diversos), mas também o cuidado em caracterizar com rigor o que é listado na Bibliografia crítica onde inclui, por exemplo, as referências que encontrou nos processos da Censura sobre textos e pedidos para a montagem cénica das suas peças.

Neste livro são de destacar três procedimentos: a avidez na pesquisa e análise da documentação a que o autor teve acesso ou que criou; a competência na sugestão do enquadramento histórico, cultural e artístico em que se desenvolve a actividade de Redol (e aqui identifico parte do programa do materialismo cultural de pensadores como Lucien Goldmann ou Raymond Williams); uma singular habilidade em identificar universos conceptuais e modelos artísticos que no campo do teatro mais terão influenciado a reflexão e a prática de Alves Redol na sua relação com o palco.

Neste campo, em particular, sublinho ainda o curioso - mas justificado - recurso à invenção de metáforas quando, no seu capítulo IV, nos fala do "diálogo com a teoria e a prática teatrais de outros", chamando à cena do pensamento objectos como "quadro, parede, lanterna, luz, espelho ou garrafa" a propósito, respectivamente, de Gorki, Antoine, Saviotti, Piscator, Brecht e Strindberg.

Com efeito, Miguel Falcão dá a ver e problematiza interpelações não apenas a autores como lbsen, Strindberg, Tchekov, Shaw, Pirandello ou Lorca, mas também a visões 

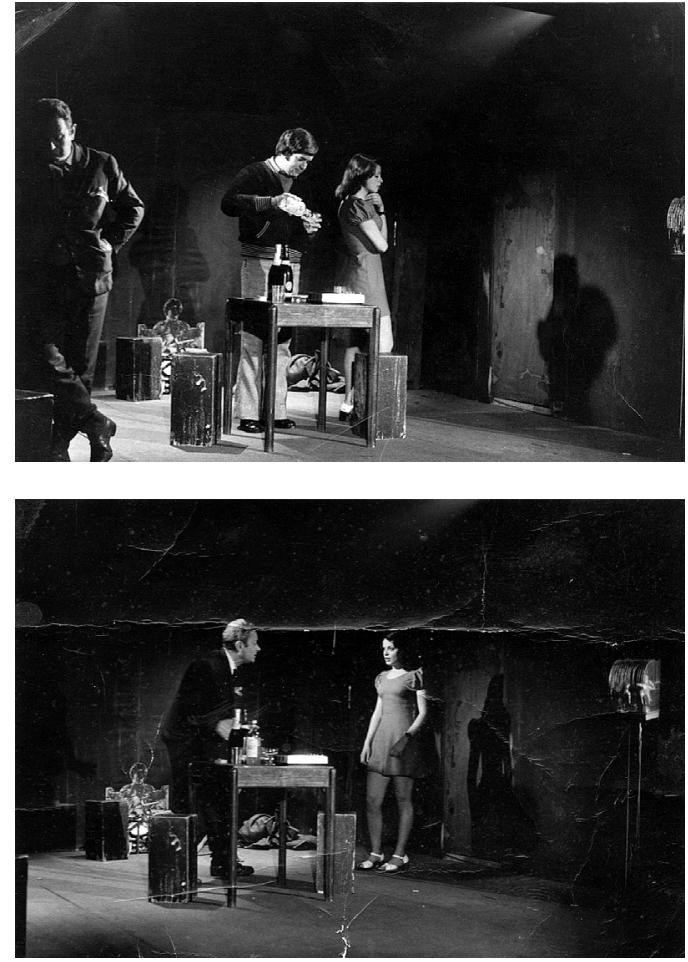

teatrais como as de Meyerhold, Eisenstein e Piscator, bem como a projectos que conheceu em França (onde esteve alguns meses depois de terminada a 2. ${ }^{a}$ guerra mundial), como o de Maurice Pottecher, Romain Roland, Firmin Gémier e o Cartel (Dullin, Baty, Jouvet e Pitoëff).

0 livro revela - documentando e interpelando - o desejo de Redol de ser "um operário das letras ao serviço de uma obra artistica colectiva" (p. 614) no planeamento de espectáculos integrados numa companhia de teatro, por exemplo. E isso não é só por enumerar textos para teatro, projectos ou realizações de Alves Redol até agora não recenseadas. É sobretudo porque a perspectiva teórica com que interroga a obra - e que descobre na obra - de Redol permite reequacionar a forma de pensar a criação teatral no contexto do que foi também o movimento artístico, cultural e político do Neo-realismo.

3.

Quatro anos depois da publicação deste Espelho de ver por dentro: 0 percurso teatral de Alves Redol, saiu um outro livro que há já muitos anos se tornava imprescindivel para melhor conhecermos essa outra faceta artistica de Alves Redol, um escritor que é célebre sobretudo como romancista, mas que, como Miguel Falcão tem vindo a provar, marcou também a escrita dramática e o teatro em Portugal.

0 livro de Alves Redol, agora dado à estampa - Teatro: Textos publicados e inéditos, com organização, introdução e notas de Miguel Falcão - reúne pela primeira vez as quatro peças já antes publicadas - Maria Emília (1945, 1966), Forja $(1948,1966), 0$ destino morreu de repente (1967), Fronteira fechada (1972, saida postumamente) -, mas acrescenta-Ihes seis inéditos "encontrados no espólio do escritor e em acervos documentais": Porto de todo o mundo (1939 a 1943?), O consórcio (até 1943?), 0 triângulo quebrado (1948 a 1949?), De braços abertos para a natureza (1950?), O menino dos olhos verdes (1950?) e Ronda do mar (1958?).

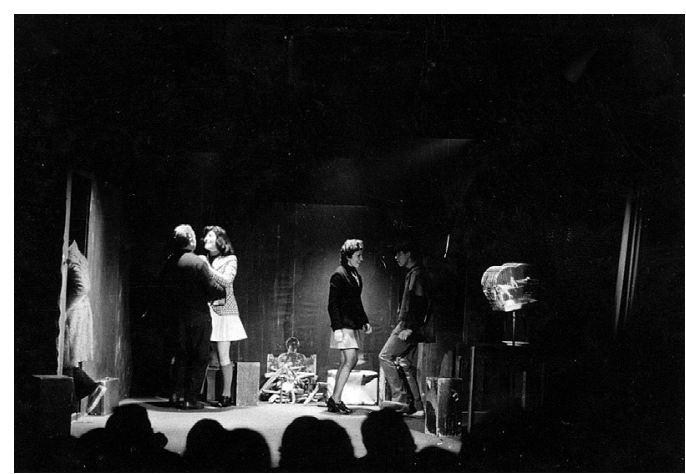

0 volume - com uma bela capa de João Tiago Marques - inclui ainda os prefácios às peças: Forja (1966), Maria Emilia (1966), 0 destino morreu de repente (1967) e Fronteira fechada (1972), que o organizador da edição decidiu - em lugar de os colocar ligados às peças - deslocar para os reunir num subconjunto que precede o grupo das 10 peças, sendo uma delas - Maria Emília - apresentada nas suas duas versões (de 1945 e de 1966). Noutros caos, em que possam existir variantes ou dúvidas (geralmente de pormenor), a opção - acertada - foi a de remeter essas observações para notas infrapaginais.

Em termos editoriais, estão assim, finalmente, saldadas as contas com a obra teatral de Alves Redol, agora acessivel em volume único editado por quem estudou a fundo a sua dramaturgia e a inseriu numa cartografia teórica e histórica que contempla não apenas a sua inserção no plano nacional, mas que a reporta a tempos e modalidades de escrita que ultrapassam a fronteira, tal como revelou no estudo que fizera já em Espelho de ver por dentro.

Acho que constitui - para a Imprensa Nacional Casa da Moeda - um notável enriquecimento da sua colecção de teatro, e que, neste caso, significa a reparação de uma lacuna na sua atenção a Alves Redol. Mas, diga-se em abono da verdade, que a Imprensa Nacional (mesmo reportando-me apenas a títulos saídos depois de 2000), tem estado, felizmente, mais atenta à dramaturgia portuguesa, tendo já editado a obra completa de autores como Luiz Francisco Rebello, Jaime Salazar Sampaio, Augusto Sobral, Teresa Rita Lopes, para além de autores menos recentes como D. João da Câmara, Fernando Amado, Ramada Curto, Tomás de Figueiredo, ou Joaquim Paço d'Arcos, entre vários outros.

Neste livro, que reúne a obra completa de Alves Redol', é visivel um cuidado editorial com que se oferecem ao público leitor - e a eventuais criadores de teatro que as queiram levar à cena - as peças de Redol em versões fidedignas e com notas explicativas - em pé de página sempre que tal se afigura necessário.

Na "Introdução" traz também Miguel Falcão ao conhecimento do leitor aspectos biográficos que ligam Redol a algumas aventuras teatrais da carácter amador - e que tinham muito que ver com iniciativas locais, a que se associava com gosto, mesmo quando Ihe era pedido que interviesse não apenas para organizar ou escrever curtas cenas, mas até para protagonizar algum quadro. Foi assim em três casos: "Largo da Estação" (o largo frente à Estação dos Caminhos de Ferro), quadro que protagonizou na revista Ida e volta (1928); uma breve cena em que fazia de Roberto na opereta Mam'zelle Nitouche (1932); e, ainda, no papel de um maioral na peça curta sobre costumes

\section{$<>$ \\ Fronteira fechada de Alves Redol, enc. Manuel Peres, SOIR Joaquim António de Aguiar, 1973 (< Manuel Peres, Adalcino Rodrigues e Isabel Bilou; $\checkmark$ Manuel Peres e Isabel Bilou),} fot Artex [Arquivo SOIR]
No contexto do lançamento do livro no Museu do Neo-realismo a 1 de Junho de 2013, António Mota Redol filho de Alves Redol esclareceu que há vários outros textos do escritor que, seguindo a

recomendação do autor continuarão inéditos. 


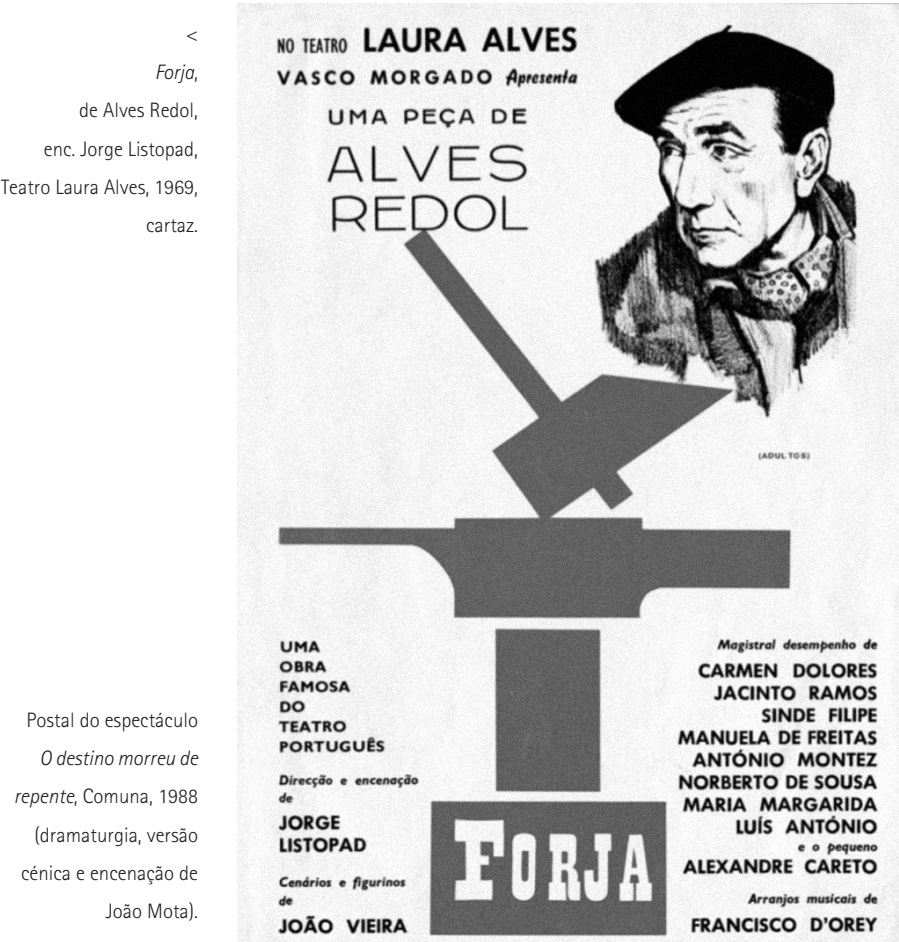

ribatejanos À sesta, de Faustino dos Reis Sousa (1932).

Fala-nos ainda - nesta sua "Introdução" - das pesquisas etnográficas que Redol conduziu e de que resultaram os livros Glória: Uma aldeia do Ribatejo (1938), Cancioneiro do Ribatejo (1950) e Romanceiro geral do povo português (este em fascículos publicados entre1959 e1964). Nesse trabalho de campo, a que se entregou, Alves Redol foi encontrar também matéria e sentido para peças como Porto de todo o mundo, Maria Emília e Forja (p. 11).

Integrando, a partir de 1936, o grupo neo-realista de Vila Franca (com Dias Lourenço, Garcez da Silva e, mais tarde, Arquimedes da Silva Santos entre outros), Alves Redol participou em múltiplas iniciativas culturais que visavam "estudar e divulgar a tradição e as criações populares, e, por outro lado, promover a aproximação do povo às designadas 'cultura erudita' e 'arte culta'" (p. 12). E entre essas iniciativas contaram-se leituras públicas comentadas de obras literárias, serões de arte, cursos de alfabetização, conferências, excursões e passeios pelo Tejo, entre várias outras actividades que tiveram o apoio do jornal 0 diabo.

Na relação que Redol estabeleceu com o contexto cultural e político em que viveu, a sua obra surge, na opinião de Miguel Falcão, como "um contributo para se entender o povo, não como um enfeite folclórico ou um quase produto turistico (aproveitamento que o regime

${ }^{2}$ Aos 16 anos, tendo completado o Curso Elementar do Comércio Alves Redol emigrou, por iniciativa própria, para Angola, para ajudar as finanças da familia e por

lá ficou três anos, regressando em 193 também pelas mãos de António Ferro lhe deu), mas como uma força culturalmente viva, com potencialidades e contradições" (p. 10).

Sinalizando a sua produção escrita para periódicos de Vila Franca, maioritariamente oposicionistas, Miguel Falcão destaca também uma das suas conferências - a outra vertente da sua actividade cívica e cultural de pretos - Ambição de brancos", que resultava da sua experiência africana ${ }^{2}$. Esta conferência foi depois repetida em Fevereiro de 1934 no Núcleo de Cultura Intelectual apresentada no Grémio Artístico Vilafranquense: "Terra

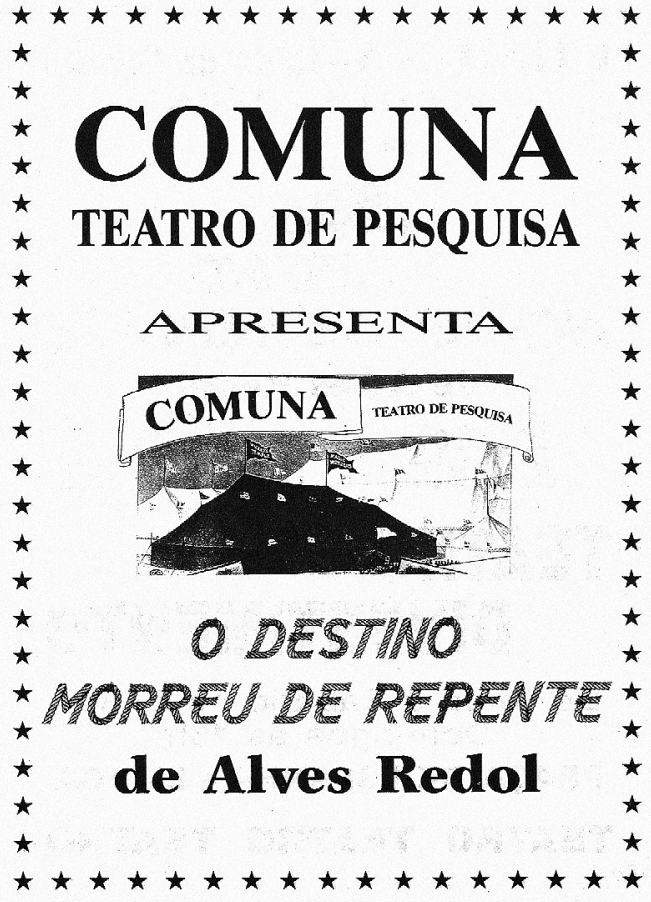

de Belém, em Lisboa "poucos meses antes da inauguração da I Exposição Colonial Portuguesa, no Porto, 'através da qual o regime enalteceria os feitos de Portugal como 'potência colonial'" (p. 11). E essa era a visão completamente oposta à que Redol apresentara na sua conferência.

Importante terá sido também - e de maior exigência do ponto de vista formal - a relação de Alves Redol com o Círculo de Cultura Teatral (1945) e o Teatro-Estúdio do Salitre (1946), ambos criados no contexto do Instituto Italiano de Cultura, ao lado de Gino Saviotti (director da instituição), Jorge de Faria, Luiz Francisco Rebello e Eduardo Scarlatti, entre outros. Foi ai que se estrearam as suas peças Maria Emilia (1946) e 0 menino dos olhos verdes (1950), tendo sido esta última escrita propositadamente para Laura Alves que, muito jovem ainda, brilhou neste seu trabalho a solo.

$\mathrm{Na}$ "Introdução", com que Miguel Falcão abre este volume, chegam-nos ainda várias outras informações utilíssimas - algumas cruciais para a datação de textos e respectivas publicações (é o caso de Forja, em edição de autor, que é de 1948 e não 1942) - e ainda importantes comentários e esclarecimentos relativamente à actuação de Redol na sua relação com o teatro, bem como a referência à leitura de autores estrangeiros, etc.

Uma das questões teóricas, que Miguel Falcão aborda nesta sua "Introdução", tem a ver com a relação - nem sempre pacifica - entre os autores da presença e do Neorealismo, acompanhando argumentos de ambos os lados e procurando, no limite, encontrar linhas de alguma confluência - mesmo que não admitida em ambos os lados - entre as duas tendências literárias.

$\mathrm{Se}$, efectivamente, pode fazer sentido discutir e reavaliar um certo enquistamento de argumentos nos dois lados desta divergência, a verdade é que algumas das razões adiantadas nesta "Introdução" podem confundir a lógica de relações pelo facto de se atribuírem - com 

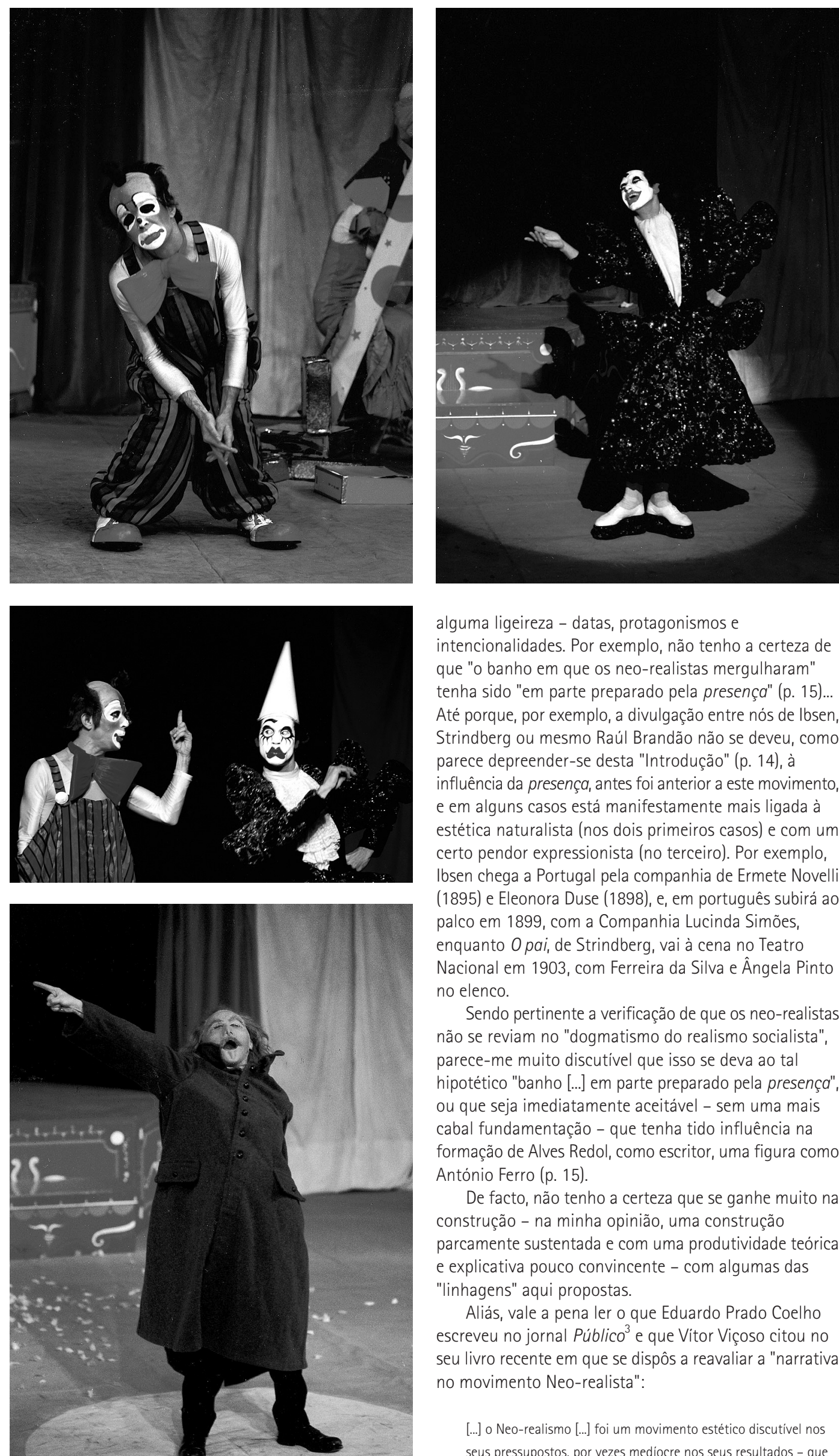

alguma ligeireza - datas, protagonismos e

intencionalidades. Por exemplo, não tenho a certeza de que "o banho em que os neo-realistas mergulharam" tenha sido "em parte preparado pela presença" (p. 15)... Até porque, por exemplo, a divulgação entre nós de lbsen, Strindberg ou mesmo Raúl Brandão não se deveu, como parece depreender-se desta "Introdução" (p. 14), à influência da presença, antes foi anterior a este movimento, e em alguns casos está manifestamente mais ligada à estética naturalista (nos dois primeiros casos) e com um certo pendor expressionista (no terceiro). Por exemplo, Ibsen chega a Portugal pela companhia de Ermete Novelli (1895) e Eleonora Duse (1898), e, em português subirá ao palco em 1899, com a Companhia Lucinda Simões, enquanto 0 pai, de Strindberg, vai à cena no Teatro Nacional em 1903, com Ferreira da Silva e Ângela Pinto no elenco.

Sendo pertinente a verificação de que os neo-realistas não se reviam no "dogmatismo do realismo socialista", parece-me muito discutivel que isso se deva ao tal hipotético "banho [...] em parte preparado pela presença", ou que seja imediatamente aceitável - sem uma mais cabal fundamentação - que tenha tido influência na formação de Alves Redol, como escritor, uma figura como António Ferro (p. 15).

De facto, não tenho a certeza que se ganhe muito na construção - na minha opinião, uma construção parcamente sustentada e com uma produtividade teórica e explicativa pouco convincente - com algumas das "linhagens" aqui propostas.

Aliás, vale a pena ler o que Eduardo Prado Coelho escreveu no jornal Público ${ }^{3}$ e que Vitor Viçoso citou no seu livro recente em que se dispôs a reavaliar a "narrativa no movimento Neo-realista":

[...] o Neo-realismo [...] foi um movimento estético discutivel nos seus pressupostos, por vezes mediocre nos seus resultados - que
$<>$

$\vee$

Odestino morreu de

repente,

de Alves Redol,

enc. João Mota, Comuna

- Teatro de Pesquisa, 1988

(< Carlos Paulo;

$>$ Alexandre Lopes:

$\checkmark$ Carlos Paulo

e Alexandre Lopes;

$\vee$ Cucha Carvalheiro),

[Arquivo da Comuna

Teatro de Pesquisa].
Público, 27 de Outubro de 2000. 

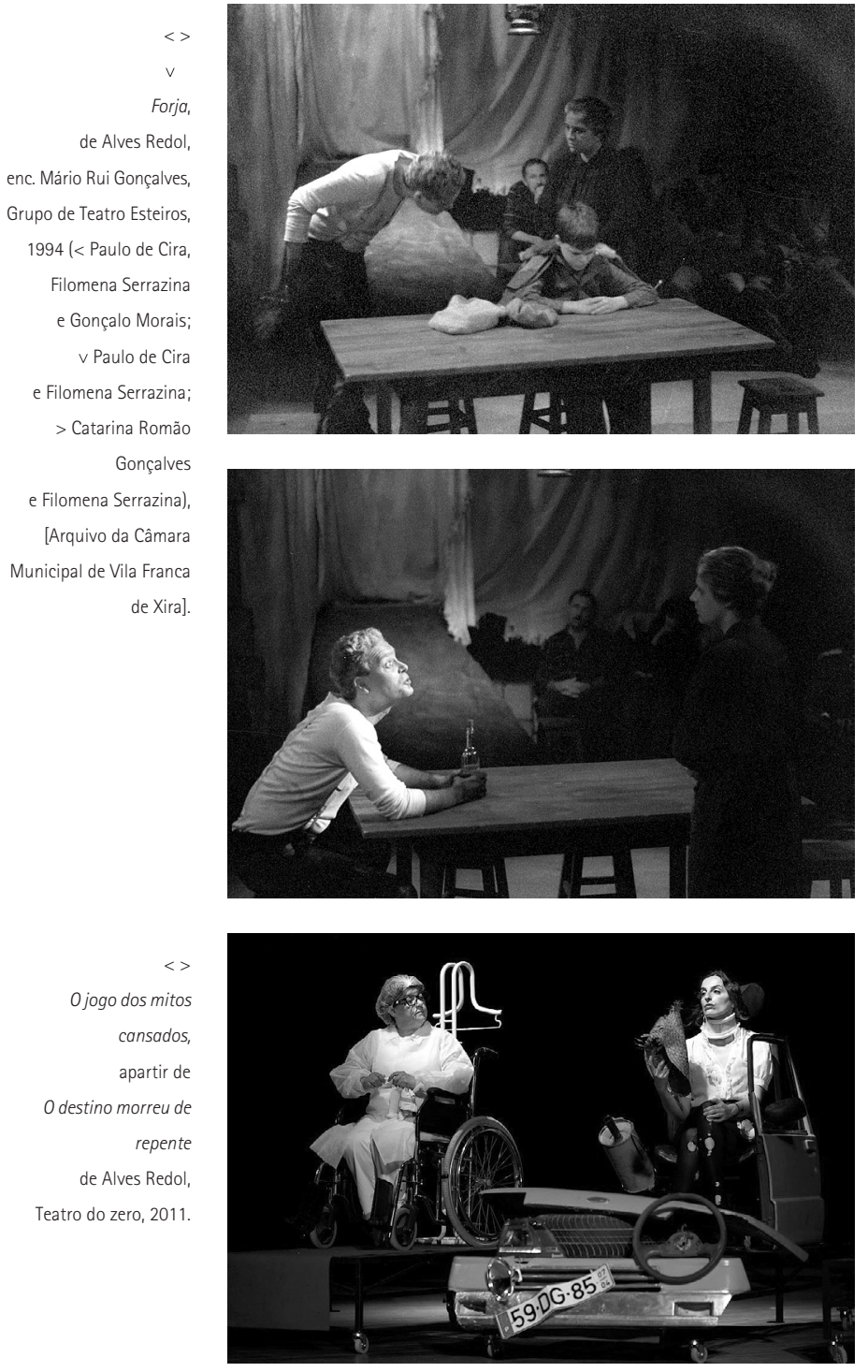

importa? Deu-nos, no entanto, autores fundamentais, livros

fundamentais - de Manuel da Fonseca e Lopes Graça ou Carlos de Oliveira. E foi um movimento estético que aparecia sobrecarregado pela responsabilidade de ser a expressão possivel, em situação de repressão e censura, de um movimento político. E esse movimento politico, com todos os erros, intolerâncias, dogmatismos e violências, constituiu entre nós o essencial da resistência ao fascismo. (Coelho apud Viçoso 2011: 13)

Independentemente da - saudável - polémica que uma ou outra afirmação possam suscitar, a verdade é que o livro que Miguel Falcão organizou com um precioso cuidado editorial e um bom aparato crítico, pelo facto de trazer à leitura - e ao estudo crítico - a obra dramática completa de Alves Redol, é um trabalho muito útil e meritório. E não será menos positivo o facto de permitir estas e muitas outras questionações que, sem este livro, dificilmente seriam possiveis, e, ainda, o de se oferecer a obra completa de Alves Redol a criadores teatrais que queiram revisitar a dramaturgia portuguesa.

Por todas estas razões, é de felicitar Miguel Falcão pelo trabalho que aqui realizou, a Imprensa NacionalCasa da Moeda por ter disponibilizado este volume, o Museu do Neo-Realismo por todo o apoio que deu à
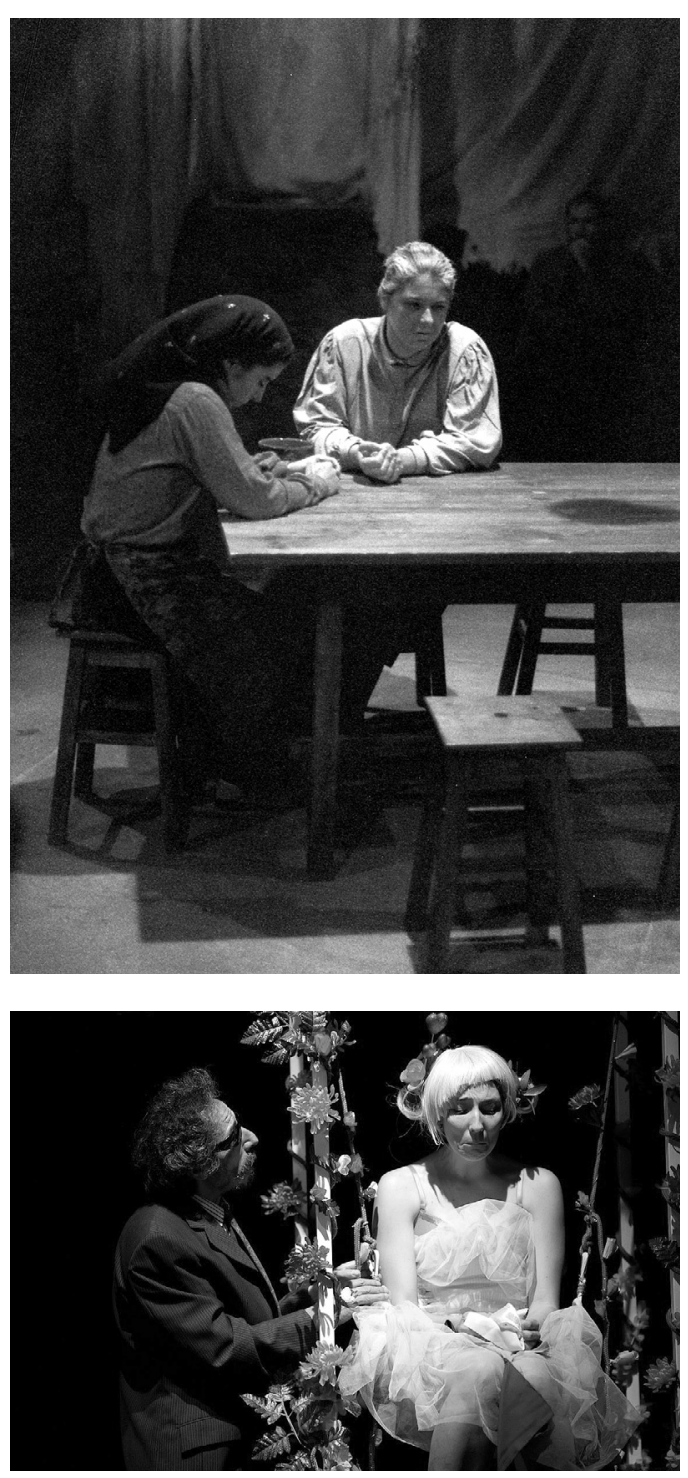

investigação que está a montante desta publicação, bem como a familia de Alves Redol que vê assim publicamente consagrada esta outra vertente criativa do escritor.

E para não esquecer o impacto emotivo da dramaturgia redoliana, gostaria de sublinhar a belíssima criação de figuras femininas que estão aqui disponíveis para um importante protagonismo de actrizes que as queiram recriar em cena.

\section{Referência bibliográfica}

VIÇOSO, Vitor (2011), A narrativa no movimento neo-realista: As vozes sociais e os universos da ficção, Lisboa, Colibri.

\section{Sitiografia}

http://cvc.instituto-camoes.pt/teatro-em-portugal-pessoas-lista/2159antonio-alves-redol.htm 